\title{
CHARACTERIZING THREE-DIMENSIONAL WAVE-DRIVEN MORPHOLOGICAL DIFFUSIVITY IN THE NEARSHORE
}

\author{
Julia Hopkins, Delft University of Technology, jhopkins@whoi.edu \\ Matthieu A. de Schipper, Delft University of Technology, M.A.deSchipper@tudelft.nl
}

\begin{abstract}
INTRODUCTION
Accurate predictions of the fate of sand nourishments in the nearshore are critical to the management of eroding shorelines. The effectiveness of these nourishments depends on wave and current conditions, which vary with nourishment shape, size, and location. Here, observations of artificial sand mounds, including a new laboratory experiment, are examined to characterize the impact of a range of wave and current conditions on mound evolution and to inform coastal management techniques.
\end{abstract}

\section{PREVIOUS WORK}

Field observations of sand mound evolution are often motivated by nourishment projects directed by state or national institutions. Nourishment profiles are monitored with time resolutions ranging from months to years and compared to measurements of basic wave properties. These studies focus on the general behavior of a nourishment (accrete, erode, move shoreward or not) which has reasonable agreement with water depth and wave height [Hands et al., 1997; Boers, 2005] and can broadly inform the choice of future nourishment locations. More detailed observations of both mound development and wave climate could further test the importance of specific wave properties, including sheltering, refraction, and nonlinear effects. A synthesis of these results would improve predictions of nearshore sand transport, helping nourishment design efficacy among other shoreline management applications,

Analytical models of sediment transport characterize the evolution of a nearshore sand structure as a diffusive process, with the basic relationship of bed elevation $z$ over time $t$ given as

$$
\frac{\partial z}{\partial t}=\nabla \cdot(\kappa \nabla \mathrm{z})
$$

The diffusion coefficient $\kappa$ represents multiple effects of wave and currents on sediment motion. By fitting observations of sand structures to known geometric diffusive shapes (e.g. Gaussian) and monitoring their evolution over time, the coefficient can be retrieved from field and laboratory data. However, the physical processes contained in this coefficient and their relative importance for different field conditions have not been fully characterized.

The lab environment provides a unique opportunity to dissect the coefficient in a 3D setting, without the need to initially assume the importance of certain processes as with a numerical model. Observations of a single wave condition and mound shape [Smith et al., 2017] motivate the study of multiple wave conditions proposed here.

\section{METHODS}

Experimental observations taken in early 2018 of the evolution of a sand mound in a flume will be used to distinguish the relative importance of wave shape, wave shadowing, current-driven shear stress, wave refraction, and wave energy on morphological diffusivity. Observations will be combined with (1) to determine $\kappa$ as a function of bed shear stress owing to waves and currents, and compared to previous studies on the relative importance of waves and currents to mounds both in and out of laboratory settings.

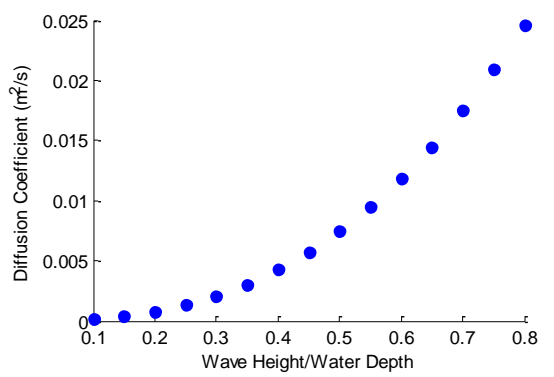

Fig 1: Diffusion coefficient as a function of relative depth for an artificial Gaussian seafloor perturbation using Soulsby (1997) wave-current shear stress formulas.

We propose a diffusion coefficient $\kappa$ that will vary both spatially and temporally to account for nonlinear interactions between mound evolution and the local response of waves and currents. The coefficient can vary vertically owing to shear stress changes as a function of depth and wave height (Fig 1) [Moulton et al., 2014] and horizontally owing to wave shadowing and refraction.

\section{DISCUSSION}

We examine previous experiments of morphological diffusivity using lab and field nearshore disturbances to identify potential balances between controlling processes based on the outline of the mound, its position, and hydrodynamic measurements. Processes considered include wave breaking, wave skewness [Thornton et al., 1996], wave orbital motion, wave shadowing, and gradients of shear stress owing to both waves and currents around a sand structure [Moulton et al., 2014] which will be discussed in the context of sediment flume experiments and numerical model results.

\section{REFERENCES}

Boers (2005), Overview of historical pits, trenches and dumpsites on the NCS, in SANDPIT: Sand transport and morphology of offshore sand mining pits

Hands, Ahrens, and Resio (1997), Predicting Large-Scale, Cross-Shore Sediment Movement from Orbital Speeds, in Coastal Engineering 1996

Moulton, Elgar, and Raubenheimer (2014), A surfzone morphological diffusivity estimated from the evolution of excavated holes, Geophys. Res. Lett

Smith, Mohr, and Chader (2017), Laboratory experiments on beach change due to nearshore mound placement, Coast. Eng.

Soulsby (1997). Dynamics of Marine Sands: A Manual for Practical Applications.

Thornton, Humiston, and Birkemeier (1996), Bar / trough generation on a natural beach, J. Geophys. Res 